\title{
INFERÊNCIAS GENÉTICAS NA PRODUÇÃO E QUALIDADE DE TOMATEIRO SOB CRUZAMENTO DIALÉLICO ${ }^{1}$
}

\author{
ANTÔNIO TEIXEIRA DO AMARAL JÚNIOR², VICENTE WAGNER DIAS CASALI ${ }^{3}$, \\ COSME DAMIÃO CRUZ ${ }^{4}$ e FERNANDO LUIZ FINGER ${ }^{5}$
}

\begin{abstract}
RESUMO - Inferências genéticas sobre o desempenho de cinco cultivares de tomateiro (Ângela I.5100, Floradade, IPA-05, Jumbo AG-592 e Santa Clara) e seus p(p-1)/2 híbridos dialélicos foram obtidas com base em três características de produção e quatro características relacionadas à qualidade dos frutos, empregando-se a metodologia de Hayman (1954). Os resultados evidenciaram a possibilidade de ganhos genéticos relativos às características de produção. O mesmo não ocorreu com os teores de sólidos solúveis, carotenóides totais e betacaroteno. Isto denota a reduzida variabilidade nas características da qualidade dos frutos avaliados.
\end{abstract}

Termos para indexação: tomate, Lycopersicon esculentum, análise dialélica, melhoramento genético, sólidos solúveis, carotenóides, betacaroteno.

\section{GENETIC INFERENCES ON YIELD AND QUALITY OF TOMATO IN A DIALLEL CROSS}

ABSTRACT - Genetic inferences on the performance of five tomato cultivars (Ângela I.5100, Floradade, IPA-05, Jumbo AG-592 and Santa Clara) and their $\mathrm{p}(\mathrm{p}$ - 1)/2 hybrids for production characteristics and fruit quality were obtained through Hayman's methodology (1954). The results showed a favorable situation for breeding to production characteristics, but not for content of soluble solids, total carotenoids, and content of betacarotene. The data evidenced low variability in the cultivars studied.

Index terms: Lycopersicon esculentum, diallelic analysis, genetic breeding, soluble solids, carotenoids, betacarotene.

\section{INTRODUÇ̃̃O}

Considerando-se a grave situação da saúde no Brasil, traduzida pelo alto índice de desnutrição, especialmente no segmento da população de baixa renda, é premente o desenvolvimento de pesquisas que visem melhorar as potencialidades das espécies em uso, com o objetivo de oferecer uma dieta de melhor valor qualitativo.

\footnotetext{
${ }^{1}$ Aceito para publicação em 10 de dezembro de 1998.

${ }^{2}$ Eng. Agr., D.Sc., Prof. Associado, Laboratório de Melhoramento Genético Vegetal, Univ. Estadual do Norte Fluminense (UENF), Av. Alberto Lamego, 200, Horto, CEP 28015-620 Campos dos Goytacazes, RJ. E-mail: amaraljr@uenf.br

${ }^{3}$ Eng. Agr., Ph.D., Prof. Tit., Dep. de Fitotecnia, Univ. Federal de Viçosa (UFV), CEP 36571-000 Viçosa, MG

${ }^{4}$ Eng. Agr., D.Sc., Prof. Tit., Dep. de Biologia Geral, UFV.

${ }^{5}$ Eng. Agr., Ph.D., Prof. Adj., Dep. de Fitotecnia, UFV.
}

Com relação ao tomateiro (Lycopersicon esculentum Mill.), essas pesquisas tornam-se ainda mais urgentes, porque o tomate apresenta deficiência em conteúdos vitamínicos (Grierson \& Kader, 1986). Para tanto, uma alternativa viável é recorrer à ampliação da base genética da espécie, via programas de melhoramento envolvendo hibridações, já que, por sua autogamia, a diversidade apresentada dentro de cada população, em geral, é inexpressiva. Nesse aspecto, o uso de cruzamentos dialélicos se mostra bastante eficiente, pois fornecem elementos para a identificação de progenitores para hibridação, ao mesmo tempo que auxiliam na escolha do método de seleção mais eficiente, por permitirem que parâmetros genéticos sejam conhecidos a priori (Cruz \& Regazzi, 1994).

Essas informações são obtidas por meio de metodologias genético-estatísticas de elevada capacidade informativa, exemplificando-se a proposta por Hayman (1954), que fornece informações sobre 
o mecanismo básico de herança da característica em estudo, dos valores genéticos dos progenitores e dos limites de seleção (Cruz \& Regazzi, 1994).

Em decorrência do elevado grau de informação extraído do Procedimento de Hayman (1954), sua aplicabilidade tem sido reportada por diversos autores em tomateiro, sobretudo na avaliação de características quantitativas de interesse ao melhoramento genético, exemplificando-se o trabalho desenvolvido por Maluf et al. (1982). Contudo, tratando-se de características relacionadas à qualidade dos frutos, tem sido observada a escassez de pesquisas afins, embora seu estudo em hortaliças seja de real importância, uma vez que nessas espécies a qualidade é tão importante quanto a quantidade produzida.

O objetivo do trabalho foi inferir o ganho genético em relação às características relacionadas à produção e à qualidade dos frutos de cinco cultivares de tomateiro e seus híbridos dialélicos.

\section{MATERIAL E MÉTODOS}

As cultivares de tomateiro Ângela I.5100 (IAC), Floradade (importada), IPA-05 (IPA), Jumbo AG-592 (Agroceres) e Santa Clara (IAC) foram utilizadas para compor um sistema de cruzamentos dialélicos, não se fazendo distinção entre os recíprocos.

Os híbridos e progenitores foram cultivados em casa de vegetação, nas dependências da Universidade Federal de Viçosa, em Viçosa, MG, no período de março a setembro de 1995, em vasos com cinco litros de capacidade, contendo uma mistura de terra, esterco e areia, na proporção de 2,5:2,5:1, respectivamente. Cada vaso recebeu $40 \mathrm{~g}$ da formulação química 4-14-8, $70 \mathrm{~g}$ de calcário e $0,9 \mathrm{~g}$ de brassicol. Adubações com micronutrientes foram realizadas em intervalos de vinte dias, totalizando oito aplicações, utilizando-se $200 \mathrm{~mL}$ por vaso da solução de Hoagland \& Arnon (1950).

O delineamento experimental utilizado foi inteiramente casualizado, com quinze tratamentos (cada qual com dez plantas) e nove repetições. Num total de dez colheitas, foram avaliadas sete características, sendo: três, relacionadas à produção, e quatro, relativas à qualidade do fruto. As características de produção foram avaliadas durante todo o ciclo da cultura, enquanto as de qualidade do fruto, à exceção do teor de sólidos solúveis, foram avaliadas em condições de laboratório, durante quinze dias, utilizando-se um fruto-padrão (característica de coloração e maturação semelhante) do terceiro cacho de cada planta. As características de produção avaliadas foram: a) número total de frutos (NTF) - obtido pela contagem de todos os frutos produzidos nas unidades experimentais; b) produção total de frutos (PTF) - expresso em g, obtido pela pesagem de todos os frutos colhidos nas unidades experimentais; c) peso médio dos frutos (PMF) - expresso em g, obtido pela razão entre PTF e NTF.

As características de qualidade dos frutos avaliadas foram: a) teor de sólidos solúveis (TSS) - expresso em ${ }^{\circ}$ Brix, obtido pelo uso de um refratômetro manual, pelo gotejamento de extrato filtrado em gaze, em uma amostra de cinco frutos de cada planta e em cada colheita; b) teor de carotenóides totais (CAROT) - expresso em $\mu \mathrm{g} / 100 \mathrm{~g}$, em uma amostra de cerca de $20 \mathrm{~g}$ do pericarpo de um fruto do terceiro cacho de cada planta; c) teor de licopeno (LICOP) - expresso em percentagem, em uma amostra de cerca de $20 \mathrm{~g}$ do pericarpo de um fruto do terceiro cacho de cada planta; d) teor de betacaroteno (BETAC) - expresso em $\mu \mathrm{g} / 100 \mathrm{~g}$, em uma amostra de cerca de $20 \mathrm{~g}$ do pericarpo de um fruto do terceiro cacho de cada planta.

As características CAROT, LICOP e BETAC foram avaliadas empregando-se a metodologia descrita por Zscheile \& Porter (1947), baseada em análise espectrofotométrica. No procedimento analítico, amostras contendo cerca de $20 \mathrm{~g}$, do pericarpo da porção mediana dos frutos, foram introduzidas em recipientes de vidro juntamente com $20 \mathrm{~mL}$ de acetona, sendo, posteriormente, cobertos com papel-alumínio, acondicionados em "freezer" e trituradas em um "becker" de $250 \mathrm{~mL}$ por meio de um misturador "Master Mix", juntamente com $60 \mathrm{~mL}$ de hexano aquecido a $60^{\circ} \mathrm{C}$. O triturado foi filtrado em filtro de porcelana contendo papel de filtro como meio separador, sob ação de vácuo. Em seguida, transferiu-se o filtrado para um funil de separação de $250 \mathrm{~mL}$, disposto verticalmente em um suporte de madeira adaptado para esse fim. Após a separação das fases, eluiu-se o imiscível basal, procedendo-se, por duas vezes, à lavagem com água destilada e eluição do sobnadante. Adicionaram-se, então, $20 \mathrm{~mL}$ de metanol a 90\%, efetuando-se a eluição do imiscível basal, após a completa separação das fases, repetindo-se a operação com as seqüenciais adições de $20 \mathrm{~mL}$ de hidróxido de potássio a $20 \%$ e $20 \mathrm{~mL}$ de metanol a $90 \%$. Retirou-se uma alíquota de $0,5 \mathrm{~mL}$ da amostra, diluindo-a com hexano, até o volume final de 6 ou $10 \mathrm{~mL}$, conforme a necessidade de adequação da leitura espectrofotométrica para intervalos de absorvância entre 0,1 e 0,6 , considerados como confiáveis. Realizaram-se, finalmente, as leituras espectrofotométricas e 
quantificaram-se os teores de carotenóides totais, licopeno e betacaroteno pelas expressões:

$\operatorname{CAROT}(\mu \mathrm{g} / \mathrm{g})=\frac{\log \left(\frac{\mathrm{I}_{0}}{\mathrm{I}}\right)(4875 \mathrm{~A}) \times \frac{\text { diluição } 1}{\text { p.a. }} \times \frac{0,5}{\text { diluição } 2} \times 10^{5}}{181 \times 1 \times \text { p.a. }}$, em que p.a. é o peso da amostra

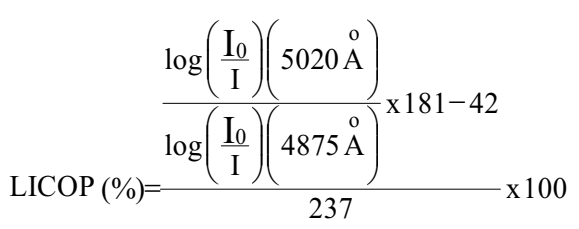

$\operatorname{BETAC}(\mu / 100 \mathrm{~g})=\frac{[100-\operatorname{LICOP}(\%)] \times \operatorname{CAROT}(\mu \mathrm{g} / \mathrm{g})}{100}$

A análise dialélica de Hayman (1954) foi implementada com base nas informações enunciadas por Cruz \& Regazzi (1994), considerando-se que os genitores homozigotos diferem em um loco $\mathbf{T} / \mathbf{t}$, com uma proporção $\mathbf{u}_{\mathbf{t}}$ de alelos favoráveis e outra $\mathbf{v}_{\mathbf{t}}$ de alelos desfavoráveis. No procedimento analítico empregaram-se os recursos computacionais do Programa Genes (Cruz, 1997).

\section{RESULTADOS E DISCUSSÃO}

Pressupondo-se que os efeitos genéticos são resultantes da ação aditiva e dominante dos genes, o método de Hayman (1954) impõe uma série de restrições, as quais requerem aplicações de testes para verificar a suficiência do modelo. Os resultados das aplicações de dois testes para as sete características avaliadas encontram-se na Tabela 1 . Constata-se que a totalidade das características manifestou ausência de significância em ambos os testes, o que evidencia a validade das pressuposições impostas e indica a viabilidade de utilização do modelo aditivo-dominante no estudo genético dessas características.

\section{Número total de frutos}

$\mathrm{Na}$ Tabela 2 estão dispostas as correlações entre o valor genotípico do i-ésimo genitor $\left(\bar{y}_{\mathrm{ii}}\right)$ e a soma da covariância e variância entre médias da i-ésima linha $\left(\hat{W}_{i}+\hat{V}_{i}\right)$, bem como os valores esperados das coordenadas $\hat{\mathrm{W}}_{\mathrm{R}}, \hat{\mathrm{V}}_{\mathrm{R}}$ e $\hat{\mathrm{W}}_{\mathrm{D}}, \hat{\mathrm{V}}_{\mathrm{D}}$ e da soma destas. Nota-se que houve correlação negativa entre $\bar{y}_{i i}$ e $\left(\hat{W}_{\mathrm{i}}+\hat{\mathrm{V}}_{\mathrm{i}}\right)$, de-0,7262, evidenciando que os alelos dominantes, em sua maioria, são responsáveis pelo aumento do número de frutos. Assim, os genitores 1, 2 e 3, por se apresentarem mais próximos da extremidade dominante da regressão de $\mathrm{W}_{\mathrm{i}}$ sobre $\mathrm{V}_{\mathrm{i}}$ (Fig. 1), seriam os genótipos mais interessantes quanto à possibilidade de seleção de linhagens com maior número de frutos. Em contraste, os genitores 4 e 5, por se afastarem dessa extremidade (Fig. 1), retêm maior concentração de alelos recessivos, sendo, por conseguinte, inadequados para tal objetivo.

O genitor com máxima homozigose dominante deveria apresentar $\hat{\mathrm{W}}_{\mathrm{i}}+\hat{\mathrm{V}}_{\mathrm{i}}=\left(\hat{\mathrm{W}}_{\mathrm{D}}+\hat{\mathrm{V}}_{\mathrm{D}}\right)=1,9689$ (Tabela 2), e o genitor 1, apesar de ter retido a maior proporção de genes dominantes, conforme classificação mostrada na Tabela 3, apresentou $\hat{\mathrm{W}}_{\mathrm{i}}+\hat{\mathrm{V}}_{\mathrm{i}}=14,8791$, indicando que há grandes possibilidades de obtenção de linhagens com maior número de frutos nas populações segregantes. A oportunidade de obtenção desses segregantes torna-se mais concreta em razão de o valor $\widetilde{\mathrm{h}}_{\mathrm{R}}^{2}$, de 0,6161 (Tabela 4), ser uma magnitude suficiente para

TABELA 1. Testes de suficiência do modelo aditivodominante, utilizando-se a metodologia de Hayman (1954), em relação a sete características avaliadas entre cinco genitores de tomateiro.

\begin{tabular}{lccc}
\hline Características $^{1}$ & Regressão $^{2}$ & & Rotação dos eixos $\hat{\mathrm{W}}_{\mathrm{i}} \quad \hat{\mathrm{V}}_{\mathrm{i}}^{3}$ \\
\cline { 2 - 2 } $\mathrm{NTF}$ & $0,2014^{\mathrm{ns}}$ & & $\mathrm{F}=\mathrm{t}^{2}\left(\mathrm{H}_{\mathrm{o}}: \mathrm{B}=\mathrm{b}-1=0\right)$ \\
\hline PTF & $-0,7885^{\mathrm{ns}}$ & $0,4232^{\mathrm{ns}}$ \\
PMF & $-0,6783^{\mathrm{ns}}$ & $0,3382^{\mathrm{ns}}$ \\
TSS & $-2,5442^{\mathrm{ns}}$ & $1,3177^{\mathrm{ns}}$ \\
CAROT & $-2,1887^{\mathrm{ns}}$ & $0,6657^{\mathrm{ns}}$ \\
LICOP & $-3,1191^{\mathrm{ns}}$ & $1,5630^{\mathrm{ns}}$ \\
BETAC & $-2,3797^{\mathrm{ns}}$ & $0,7741^{\mathrm{ns}}$ \\
\hline
\end{tabular}

${ }^{1}$ NTF: número total de frutos; PTF: peso total de frutos; PMF: peso médio dos frutos; TSS: teor de sólidos solúveis dos frutos; CAROT: conteúdo de carotenóides totais dos frutos; LICOP: percentagem de licopeno dos frutos; BETAC: teor de betacaroteno dos frutos.

2 Teste $t$, ponderando-se os valores médios de $\hat{\mathrm{W}}_{\mathrm{i}}$ e $\hat{\mathrm{V}}_{\mathrm{i}}$ a $1 \%$ e $5 \%$ de probabilidade.

${ }^{3}$ Teste $\mathrm{F}$, ponderando-se os eixos de $\hat{\mathrm{W}}_{\mathrm{i}}$ e $\hat{\mathrm{V}}_{\mathrm{i}}$, por meio de sua rotação de $45^{\circ}$, a $1 \%$ e $5 \%$ de probabilidade.

ns Não-significativo a $5 \%$ de probabilidade. 
TABELA 2. Estimativas das correlações entre o valor genotípico do i-ésimo genitor $\left(\bar{y}_{i i}\right)$ e a soma da covariância com a variância entre médias da i-ésima linha $\left(\hat{\mathrm{W}}_{\mathrm{i}}+\hat{\mathrm{V}}_{\mathrm{i}}\right)$, assim como os valores esperados das coordenadas $\hat{W}_{R}, \hat{V}_{R}$ e $\hat{W}_{D}, \hat{V}_{D}$ e da soma destas referentes a sete características avaliadas em cinco genitores de tomateiro, segundo a metodologia de Hayman (1954).

\begin{tabular}{lrrrrrrr}
\hline Características $^{1}$ & \multicolumn{7}{c}{ Valores estimados } \\
\cline { 2 - 8 } & $\mathrm{r}\left(\overline{\mathrm{y}}_{\mathrm{ii}}, \hat{\mathrm{W}}_{\mathrm{i}}+\hat{\mathrm{V}}_{\mathrm{i}}\right)$ & \multicolumn{1}{c}{$\hat{\mathrm{W}}_{\mathrm{R}}$} & \multicolumn{1}{c}{$\hat{\mathrm{V}}_{\mathrm{R}}$} & $\hat{\mathrm{W}}_{\mathrm{R}}+\hat{\mathrm{V}}_{\mathrm{R}}$ & \multicolumn{1}{c}{$\hat{\mathrm{W}}_{\mathrm{D}}$} & \multicolumn{1}{c}{$\hat{\mathrm{V}}_{\mathrm{D}}$} & $\hat{\mathrm{W}}_{\mathrm{D}}+\hat{\mathrm{V}}_{\mathrm{D}}$ \\
\hline NTF & $-0,7262$ & 77,5371 & 73,4997 & 151,0368 & 1,9237 & 0,0452 & 1,96899 \\
PTF & $-0,9265$ & $115.397,2000$ & $141.096,1000$ & $256.493,3000$ & $10.903,7900$ & $1.259,7370$ & $12.163,5270$ \\
PMF & 0,4757 & 383,7864 & 389,9529 & 773,7393 & 52,0586 & 7,1749 & 59,2335 \\
TSS & 0,0064 & 1,6663 & 4,9134 & 6,5897 & $-0,0100$ & 0,0001 & $-0,0099$ \\
CAROT & $-0,1346$ & 0,8589 & 5,8540 & 6,7129 & $-0,0149$ & 0,0017 & $-0,0132$ \\
LICOP & $-0,7308$ & 6,5017 & 27,9708 & 34,4725 & $-0,1358$ & 0,0122 & $-0,1236$ \\
BETAC & 0,1464 & 0,1518 & 1,2640 & 1,4158 & $-0,0029$ & 0,0004 & $-0,0025$ \\
\hline
\end{tabular}

${ }^{1}$ NTF: número total de frutos; PTF: peso total de frutos; PMF: peso médio dos frutos; TSS: teor de sólidos solúveis dos frutos; CAROT: teor de carotenóides totais dos frutos; LICOP: percentagem de licopeno dos frutos; BETAC: teor de betacaroteno dos frutos.

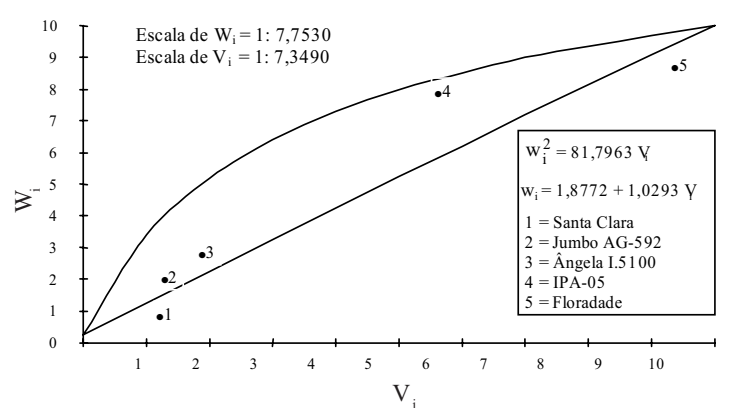

FIG. 1. Regressão de $W_{i}$ sobre $V_{i}$ em relação ao número total de frutos.

TABELA 3. Valores da soma da covariância entre médias dos genitores e médias da i-ésima linha $\left(\hat{W}_{i}\right)$ com a variância entre médias da i-ésima linha $\left(\hat{V}_{i}\right)$ e classificação da magnitude da soma em cinco genitores de tomateiro, referentes ao número total de frutos, segundo a metodologia de Hayman (1954).

\begin{tabular}{lrc}
\hline Genitor & $\hat{\mathrm{W}}_{\mathrm{i}}+\hat{\mathrm{V}}_{\mathrm{i}}$ & Classificação $^{1}$ \\
\hline 1. Santa Clara & 14,8791 & $5^{\underline{\mathrm{o}}}$ \\
2. Jumbo AG-592 & 18,4992 & $4^{\underline{\mathrm{o}}}$ \\
3. Ângela I.5100 & 27,5628 & $3^{\mathrm{o}}$ \\
4. IPA-05 & 98,0894 & $2^{\underline{\mathrm{o}}}$ \\
5. Floradade & 132,3880 & $1^{\underline{\mathrm{o}}}$ \\
\hline
\end{tabular}

1 Refere-se à ordem de concentração de alelos recessivos.
TABELA 4. Estimativas dos componentes e das informações genéticas referentes à característica número total de frutos com relação a cinco genitores de tomateiro, segundo a metodologia de Hayman (1954).

\begin{tabular}{cccc}
\hline Componentes $^{1}$ & Estimativas & Informações $^{2}$ & Estimativas \\
\hline$\widetilde{\varepsilon}$ & 4,2339 & $\sqrt{\widetilde{\mathrm{H}}_{1} / \widetilde{\mathrm{D}}}$ & 0,8284 \\
$\widetilde{\mathrm{D}}$ & 77,5624 & $\widetilde{\mathrm{H}}_{2} / 4 \widetilde{\mathrm{H}}_{1}$ & 0,2101 \\
$\widetilde{\mathrm{H}}_{1}$ & 53,2373 & $\widetilde{\mathrm{K}}_{\mathrm{D}} / \widetilde{\mathrm{K}}_{\mathrm{R}}$ & 1,0795 \\
$\widetilde{\mathrm{H}}_{2}$ & 44,7445 & $\widetilde{\mathrm{h}}^{2} / \widetilde{\mathrm{H}}_{2}$ & 0,1931 \\
$\widetilde{\mathrm{h}}^{2}$ & 8,6427 & $\widetilde{\mathrm{h}}_{\mathrm{R}}^{2}$ & 0,6161 \\
$\widetilde{\mathrm{F}}$ & 36,5563 & $\widetilde{\mathrm{h}}_{\mathrm{A}}^{2}$ & 0,8945 \\
$\widetilde{\mathrm{D}}-\widetilde{\mathrm{H}}_{1}$ & 24,3251 & & \\
\hline
\end{tabular}

${ }^{1} \widetilde{\varepsilon}$ : componente associado ao erro experimental; $\widetilde{\mathrm{D}}$ : componente associado aos efeitos aditivos; $\widetilde{\mathrm{H}}_{1}, \widetilde{\mathrm{H}}_{2} \mathrm{e} \widetilde{\mathrm{h}}^{2}$ : componentes associados aos efeitos de dominância; $\widetilde{\mathrm{F}}$ : covariância entre os efeitos aditivos e dominantes; $\widetilde{\mathrm{D}}-\widetilde{\mathrm{H}}_{1}$ : componente que expressa a diferença entre os efeitos aditivos e dominantes

$2 \sqrt{\widetilde{\mathrm{H}}_{1} / \widetilde{\mathrm{D}}}$ : grau médio de dominância; $\widetilde{\mathrm{H}}_{2} / 4 \widetilde{\mathrm{H}}_{1}$ : simetria alélica; $\widetilde{\mathrm{K}}_{\mathrm{D}} / \widetilde{\mathrm{K}}_{\mathrm{R}}$ : relação entre genes dominantes e recessivos; $\widetilde{\mathrm{h}}^{2} / \widetilde{\mathrm{H}}_{2}$ : número de genes com dominância; $\widetilde{\mathrm{h}}_{\mathrm{R}}^{2}$ : herdabilidade no sentido restrito; $\tilde{\mathrm{h}}_{\mathrm{A}}^{2}$ : herdabilidade no sentido amplo.

concluir pela fidedignidade da transmissão dos alelos desejáveis a futuras gerações.

No tocante às estimativas dos componentes genéticos, percebe-se, na Tabela 4, a maior impor- 
tância dos componentes associados aos efeitos aditivos $(\widetilde{\mathrm{D}}=77,5624)$ do que aos relacionados com efeitos de dominância $\left(\widetilde{\mathrm{H}}_{1}=53,2373\right.$; $\widetilde{\mathrm{H}}_{2}=44,7445 ;$ e $\left.\widetilde{\mathrm{h}}^{2}=8,6427\right)$, o que é evidenciado também pelo valor positivo de $\widetilde{\mathrm{D}}-\widetilde{\mathrm{H}}_{1}$. A dominância completa parece ser a relação gênica atuante na expressão do número de frutos, tendo em vista a estatística $\sqrt{\widetilde{\mathrm{H}}_{1} / \widetilde{\mathrm{D}}}$ revelar o valor 0,8284 , próximo de 1,0 (Tabela 4).

A estimativa do número de genes que exibem dominância foi de 0,1931 (Tabela 4). Contudo, é oportuno ressaltar que a expressão $\widetilde{\mathrm{h}}^{2} / \widetilde{\mathrm{H}}_{2}$ é válida quando os valores genotípicos do heterozigoto $\left(\mathrm{h}_{\mathrm{t}}\right)$ que não são nulos são diferentes em magnitude, e quando é nula a diferença entre a freqüência de genitores em homozigose dominante e a freqüência de genitores em homozigose recessiva (estatística de valor paramétrico $\mathrm{w}_{\mathrm{t}}$ ), o que ocorre quando $\widetilde{\mathrm{H}}_{1}-\widetilde{\mathrm{H}}_{2} \sim 0$ (Carvalho, 1993). No presente caso, como $\widetilde{\mathrm{H}}_{1}-\widetilde{\mathrm{H}}_{2}$ pode ser considerado aproximadamente igual a zero, deduz-se que os genes dominantes e recessivos estão igualmente distribuídos entre os pais. Tal dedução pode ser comprovada pela estatística $\widetilde{\mathrm{K}}_{\mathrm{D}} / \widetilde{\mathrm{K}}_{\mathrm{R}}$, para a qual o valor de 1,0795 (Tabela 4) indica que a variância entre as médias da i-ésima linha equipara-se à variância média. Essa simetria pode também ser inferida pelo produto da freqüência de alelos favoráveis e desfavoráveis $\left(\mathrm{u}_{\mathrm{t}} \mathrm{v}_{\mathrm{t}}\right)$, o qual deve ser próximo de 0,25 , quando $\mathrm{w}_{\mathrm{t}}=0$, ou seja, $50 \%$ dos pais têm alelos favoráveis e $50 \%$, desfavoráveis. Neste caso, o estimador $\mathrm{u}_{\mathrm{t}} \mathrm{v}_{\mathrm{t}}$, dado por $\widetilde{\mathrm{H}}_{2} / 4 \widetilde{\mathrm{H}}_{1}$, foi de 0,2101 (Tabela 4 ), o que confirma a simetria.

\section{Peso total de frutos}

Os alelos dominantes também contribuem para elevações em suas magnitudes, tendo em vista o valor de $-0,9265$ para a correlação entre $\bar{y}_{i i}$ e $\hat{\mathrm{W}}_{\mathrm{i}}+\hat{\mathrm{V}}_{\mathrm{i}}$ (Tabela 2). A ordem dos genitores, em relação à concentração de alelos dominantes, é 3, 5, 1,2 e 4 (Tabela 5), com 2 e 4 mostrando maior número de genes recessivos, o que também pode ser atestado na Fig. 2.

A Fig. 2 evidencia a possibilidade de obtenção de segregantes ainda mais dominantes, o que pode ser constatado pelo fato de que o genitor 3 , embora seja o de maior concentração de alelos dominantes, cujo valor de $\hat{\mathrm{W}}_{\mathrm{i}}+\hat{\mathrm{V}}_{\mathrm{i}}=52.076,8203$ (Tabela 5), ainda é inferior ao que poderá alcançar, ou seja, 12.163,5270 (Tabela 2).

À semelhança de NTF, o efeito aditivo também se fez mais presente em PTF, uma vez que o valor de $\widetilde{\mathrm{D}}=81.520,0781$ se sobrepôs às suas contrapartes dominantes, com $\widetilde{\mathrm{H}}_{1}=43.989,3632$; $\widetilde{\mathrm{H}}_{2}=26.726,0683$; e $\widetilde{\mathrm{h}}^{2}=28.123,0761$ (Tabela 6).

A confiabilidade na obtenção de segregantes desejáveis foi mais pronunciada em PTF do que em NTF, em decorrência do coeficiente de determinação genotípica apresentado, de 0,7059 (Tabela 6), no tocante àquela característica. A simetria alélica foi retratada pela estatística $\widetilde{K}_{D} / \widetilde{K}_{R}$, em que o

TABELA 5. Valores da soma da covariância entre médias dos genitores e médias da i-ésima linha $\left(\hat{W}_{i}\right)$ com a variância entre médias da i-ésima linha $\left(\hat{V}_{i}\right)$ e classificação da magnitude da soma quanto a cinco genitores de tomateiro, em relação ao peso total de frutos, segundo a metodologia de Hayman (1954).

\begin{tabular}{lrc}
\hline Genitor & $\hat{\mathrm{W}}_{\mathrm{i}}+\hat{\mathrm{V}}_{\mathrm{i}}$ & Classificação $^{1}$ \\
\hline 1. Santa Clara & $78.595,3437$ & $3^{\mathrm{o}}$ \\
2. Jumbo AG-592 & $81.638,5546$ & $2^{\underline{\mathrm{o}}}$ \\
3. Ângela I.5100 & $52.076,8203$ & $5^{\mathrm{o}}$ \\
4. IPA-05 & $140.874,7500$ & $1^{\mathrm{o}}$ \\
5. Floradade & $72.251,2031$ & $4^{\mathrm{o}}$ \\
\hline
\end{tabular}

${ }^{1}$ Refere-se à ordem de concentração de alelos recessivos.

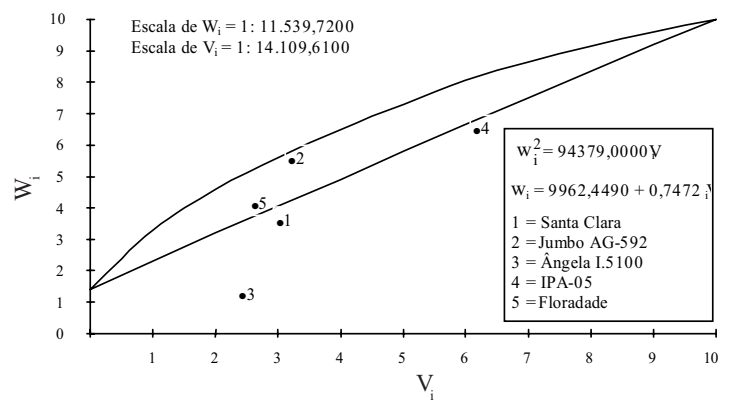

FIG. 2. Regressão de $W_{i}$ sobre $V_{i}$ em relação ao peso total de frutos.

Pesq. agropec. bras., Brasília, v.34, n.8, p.1407-1416, ago. 1999 
valor expresso $(1,0864)$ se aproximou nitidamente da unidade (Tabela 6).

Pode-se destacar a pequena confiabilidade da estatística $\widetilde{\mathrm{h}}^{2} / \widetilde{\mathrm{H}}_{2}$, por revelar resultados de mínima robustez, quando se comparam as caractetísticas NTF e PTF. Para a primeira, em que a dominância completa se fez presente, sequer um gene dominante esteve envolvido na sua expressão, como pode ser observado pelo valor exibido, igual a 0,1931 (Tabela 4), enquanto em PTF, em que a parcialidade na dominância parece ter sido a relação gênica atuante, verificou-se um valor maior, expresso por 1,0522 gene dominante atuando na expressão dessa característica (Tabela 6). Por conseguinte, o estimador $\widetilde{h}^{2} / \widetilde{H}_{2}$ deve ser observado com certo grau de ceticismo, uma vez que atipicidades dessa natureza também foram constatadas por Carvalho (1993), em trabalho envolvendo a análise dialélica de Hayman (1954) em cultivares de algodão.

TABELA 6. Estimativas dos componentes e das informações genéticas referentes à característica peso total de frutos com relação a cinco genitores de tomateiro, segundo a metodologia de Hayman (1954).

\begin{tabular}{cccc}
\hline Componentes $^{1}$ & Estimativas & Informações $^{2}$ & Estimativas \\
\hline$\widetilde{\varepsilon}$ & $12.858,9199$ & $\sqrt{\widetilde{\mathrm{H}}_{1} / \widetilde{\mathrm{D}}}$ & 0,7345 \\
$\widetilde{\mathrm{D}}$ & $81.520,0781$ & $\widetilde{\mathrm{H}}_{2} / 4 \widetilde{\mathrm{H}}_{1}$ & 0,1518 \\
$\widetilde{\mathrm{H}}_{1}$ & $43.989,3632$ & $\widetilde{\mathrm{K}}_{\mathrm{D}} / \widetilde{\mathrm{K}}_{\mathrm{R}}$ & 1,0864 \\
$\widetilde{\mathrm{H}}_{2}$ & $26.726,0683$ & $\widetilde{\mathrm{h}}^{2} / \widetilde{\mathrm{H}}_{2}$ & 1,0522 \\
$\widetilde{\mathrm{h}}^{2}$ & $28.123,0761$ & $\widetilde{\mathrm{h}}_{\mathrm{R}}^{2}$ & 0,7059 \\
$\widetilde{\mathrm{F}}$ & $4.963,1396$ & $\widetilde{\mathrm{h}}_{\mathrm{A}}^{2}$ & 0,8064 \\
$\widetilde{\mathrm{D}}-\widetilde{\mathrm{H}}_{1}$ & $37.530,7148$ & & \\
\hline
\end{tabular}

$1 \widetilde{\varepsilon}$ : componente associado ao erro experimental; $\widetilde{\mathrm{D}}$ : componente associado aos efeitos aditivos; $\widetilde{\mathrm{H}}_{1}, \widetilde{\mathrm{H}}_{2}$ e $\widetilde{\mathrm{h}}^{2}$ : componentes associados aos efeitos de dominância; $\widetilde{\mathrm{F}}$ : covariância entre os efeitos aditivos e dominantes; $\widetilde{\mathrm{D}}-\widetilde{\mathrm{H}}_{1}$ : componente que expressa a diferença entre os efeitos aditivos e dominantes.

$2 \sqrt{\widetilde{\mathrm{H}}_{1} / \widetilde{\mathrm{D}}}$ : grau médio de dominância; $\widetilde{\mathrm{H}}_{2} / 4 \widetilde{\mathrm{H}}_{1}$ : simetria alélica; $\widetilde{\mathrm{K}}_{\mathrm{D}} / \widetilde{\mathrm{K}}_{\mathrm{R}}$ : relação entre genes dominantes e recessivos; $\widetilde{\mathrm{h}}^{2} / \widetilde{\mathrm{H}}_{2}$ : número de genes com dominância; $\widetilde{\mathrm{h}}_{\mathrm{R}}^{2}$ : herdabilidade no sentido restrito; $\widetilde{\mathrm{h}}_{\mathrm{A}}^{2}$ : herdabilidade no sentido amplo.

Pesq. agropec. bras., Brasília, v.34, n.8, p.1407-1416, ago. 1999

\section{Peso médio dos frutos}

Considerando-se a correlação entre $\bar{y}_{\mathrm{ii}}$ e $\left(\hat{\mathrm{W}}_{\mathrm{i}}+\hat{\mathrm{V}}_{\mathrm{i}}\right)$, o valor de 0,4757 (Tabela 2 ) evidencia que os alelos que atuam no sentido de aumentar o peso médio dos frutos tendem a ser predominantemente, mas não exclusivamente, recessivos. Nesse caso, os genitores mais apropriados para obtenção de linhagens superiores são o 4 e o 5 , por se encontrarem mais próximos do limite de concentração de alelos recessivos (Fig. 3), embora tenha ficado aquém do valor máximo que poderia ser obtido (773,7393), conforme pode ser visualizado na Tabela 2, tendo em vista os respectivos valores de 456,9072 e 476,6325 para $\hat{\mathrm{W}}_{\mathrm{i}}+\hat{\mathrm{V}}_{\mathrm{i}}$ (Tabela 7).

$\mathrm{O}$ valor positivo do componente $\widetilde{\mathrm{D}}-\widetilde{\mathrm{H}}_{1}$ (Tabela 8) atesta que os efeitos aditivos são mais importantes que os de dominância na expressão da característica. A relação $\widetilde{\mathrm{H}}_{2} / 4 \widetilde{\mathrm{H}}_{1}$, que estima o produto da freqüência dos alelos favoráveis e desfavoráveis $\left(\mathrm{u}_{\mathrm{t}} \mathrm{v}_{\mathrm{t}}\right)$, é igual a 0,2095 (Tabela 8), o que mostra simetria dos genes. Entretanto, a relação $\widetilde{\mathrm{K}}_{\mathrm{D}} / \widetilde{\mathrm{K}}_{\mathrm{R}}$, que estima a relação média do número de genes dominantes e recessivos, indica assimetria, donde se conclui pela baixa precisão na estimativa de $\widetilde{\mathrm{F}}$.

\section{Teor de sólidos solúveis dos frutos}

A correlação entre $\bar{y}_{i i}$ e $\left(\hat{W}_{\mathrm{i}}+\hat{\mathrm{V}}_{\mathrm{i}}\right)$ foi positiva, porém próxima de zero $(0,0064)$ (Tabela 2$)$, o que mostra ausência de dominância direcional. Os efeitos de dominância foram preponderantes sobre os aditivos, em razão do valor -1,2721 na relação

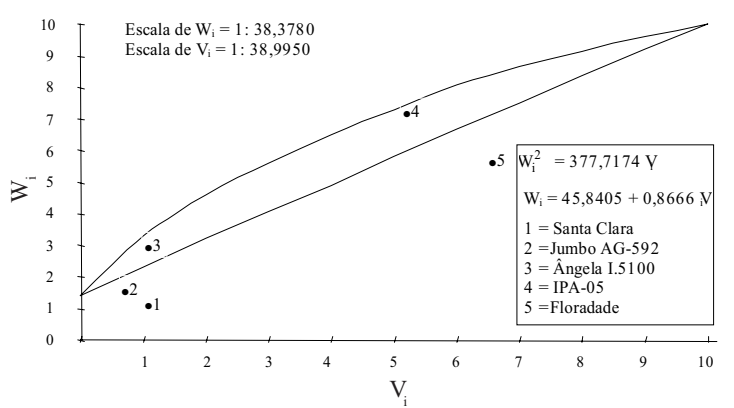

FIG. 3. Regressão de $W_{i}$ sobre $V_{i}$ em relação ao peso médio de frutos. 
$\widetilde{\mathrm{D}}-\widetilde{\mathrm{H}}_{1}$ (Tabela 9). A sobredominância é a interação prevalecente, em decorrência do valor 1,8223 apresentado pelo estimador $\sqrt{\widetilde{\mathrm{H}}_{1} / \widetilde{\mathrm{D}}}$, o que

TABELA 7. Valores da soma da covariância entre médias dos genitores e médias da i-ésima linha $\left(\hat{W}_{i}\right)$ com a variância entre médias da i-ésima linha $\left(\hat{V}_{i}\right)$ e classificação da magnitude da soma referentes a cinco genitores de tomateiro, em relação ao peso médio dos frutos, segundo a metodologia de Hayman (1954).

\begin{tabular}{lrc}
\hline Genitor & $\hat{\mathrm{W}}_{\mathrm{i}}+\hat{\mathrm{V}}_{\mathrm{i}}$ & Classificação $^{1}$ \\
\hline 1. Santa Clara & 73,7830 & $4^{\underline{\mathrm{o}}}$ \\
2. Jumbo AG-592 & 72,3601 & $5^{\mathrm{o}}$ \\
3. Ângela I.5100 & 101,4437 & $3^{\underline{\mathrm{o}}}$ \\
4. IPA-05 & 456,9072 & $2^{\mathrm{o}}$ \\
5. Floradade & 476,6325 & $1^{\underline{\mathrm{o}}}$ \\
\hline
\end{tabular}

${ }^{1}$ Refere-se à ordem de concentração de alelos recessivos.

TABELA 8. Estimativas dos componentes e das informações genéticas referentes à característica peso médio dos frutos com relação a cinco genitores de tomateiro, segundo a metodologia de Hayman (1954).

\begin{tabular}{crcc}
\hline Componentes $^{1}$ & Estimativas & Informações $^{2}$ & Estimativas \\
\hline$\widetilde{\varepsilon}$ & 8,9575 & $\sqrt{\widetilde{\mathrm{H}}_{1} / \widetilde{\mathrm{D}}}$ & 0,7566 \\
$\widetilde{\mathrm{D}}$ & 368,7598 & $\widetilde{\mathrm{H}}_{2} / 4 \widetilde{\mathrm{H}}_{1}$ & 0,2095 \\
$\widetilde{\mathrm{H}}_{1}$ & 211,1438 & $\widetilde{\mathrm{K}}_{\mathrm{D}} / \widetilde{\mathrm{K}}_{\mathrm{R}}$ & 2,1861 \\
$\widetilde{\mathrm{H}}_{2}$ & 176,9635 & $\widetilde{\mathrm{h}}^{2} / \widetilde{\mathrm{H}}_{2}$ & 0,0639 \\
$\widetilde{\mathrm{h}}^{2}$ & 11,3172 & $\widetilde{\mathrm{h}}_{\mathrm{R}}^{2}$ & 0,6471 \\
$\widetilde{\mathrm{F}}$ & 207,7591 & $\widetilde{\mathrm{h}}_{\mathrm{A}}^{2}$ & 0,9405 \\
$\widetilde{\mathrm{D}}-\widetilde{\mathrm{H}}_{1}$ & 157,6160 & & \\
\hline
\end{tabular}

$\widetilde{\varepsilon}$ : componente associado ao erro experimental; $\widetilde{\mathrm{D}}:$ componente associado aos efeitos aditivos; $\widetilde{\mathrm{H}}_{1}, \widetilde{\mathrm{H}}_{2} \mathrm{e} \widetilde{\mathrm{h}}^{2}$ : componentes associados aos efeitos de dominância; $\widetilde{\mathrm{F}}$ : covariância entre os efeitos aditivos e dominantes; $\widetilde{\mathrm{D}}-\widetilde{\mathrm{H}}_{1}$ : componente que expressa a diferença entre os efeitos aditivos e dominantes.

$2 \sqrt{\widetilde{\mathrm{H}}_{1} / \widetilde{\mathrm{D}}}$ : grau médio de dominância; $\widetilde{\mathrm{H}}_{2} / 4 \widetilde{\mathrm{H}}_{1}$ : simetria alélica; $\widetilde{\mathrm{K}}_{\mathrm{D}} / \widetilde{\mathrm{K}}_{\mathrm{R}}$ : relação entre genes dominantes e recessivos; $\widetilde{\mathrm{h}}^{2} / \widetilde{\mathrm{H}}_{2}$ : número de genes com dominância; $\widetilde{\mathrm{h}}_{\mathrm{R}}^{2}$ : herdabilidade no sentido restrito; $\widetilde{\mathrm{h}}_{\mathrm{A}}^{2}$ : herdabilidade no sentido amplo também pode ser constatado na Fig. 4, na qual a linha de regressão corta o eixo $\mathrm{W}_{\mathrm{i}}$ abaixo da origem. A simetria alélica é destacada pelo valor 0,2222 em $\widetilde{\mathrm{H}}_{2} / 4 \widetilde{\mathrm{H}}_{1}$. O coeficiente de determinação genotípica apresentou-se com magnitude bastante reduzida $(0,2402)$, indicando que métodos

TABELA 9. Estimativas dos componentes e das informações genéticas referentes à característica teor de sólidos solúveis dos frutos, com relação a cinco genitores de tomateiro, segundo a metodologia de Hayman (1954).

\begin{tabular}{cccc}
\hline Componentes $^{1}$ & Estimativas $^{\text {Informações }^{2}}$ & Estimativas \\
\hline$\widetilde{\varepsilon}$ & 0,0170 & $\sqrt{\widetilde{\mathrm{H}}_{1} / \widetilde{\mathrm{D}}}$ & 1,8223 \\
$\widetilde{\mathrm{D}}$ & 0,5480 & $\widetilde{\mathrm{H}}_{2} / 4 \widetilde{\mathrm{H}}_{1}$ & 0,2222 \\
$\widetilde{\mathrm{H}}_{1}$ & 1,8202 & $\widetilde{\mathrm{K}}_{\mathrm{D}} / \widetilde{\mathrm{K}}_{\mathrm{R}}$ & 1,6393 \\
$\widetilde{\mathrm{H}}_{2}$ & 1,6178 & $\widetilde{\mathrm{h}}^{2} / \widetilde{\mathrm{H}}_{2}$ & 0,5552 \\
$\widetilde{\mathrm{h}}^{2}$ & 0,8982 & $\widetilde{\mathrm{h}}_{\mathrm{R}}^{2}$ & 0,2402 \\
$\widetilde{\mathrm{F}}$ & 0,4838 & $\widetilde{\mathrm{h}}_{\mathrm{A}}^{2}$ & 0,9693 \\
$\widetilde{\mathrm{D}}-\widetilde{\mathrm{H}}_{1}$ & $-1,2721$ & & \\
\hline
\end{tabular}

$1 \widetilde{\varepsilon}$ : componente associado ao erro experimental; $\widetilde{\mathrm{D}}$ : componente associado aos efeitos aditivos; $\widetilde{\mathrm{H}}_{1}, \widetilde{\mathrm{H}}_{2} \mathrm{e} \widetilde{\mathrm{h}}^{2}$ : componentes associados aos efeitos de dominância; $\widetilde{\mathrm{F}}$ : covariância entre os efeitos aditivos e dominantes; $\widetilde{\mathrm{D}}-\widetilde{\mathrm{H}}_{1}$ : componente que expressa a diferença entre os efeitos aditivos e dominantes.

$2 \sqrt{\widetilde{\mathrm{H}}_{1} / \widetilde{\mathrm{D}}}$ : grau médio de dominância; $\widetilde{\mathrm{H}}_{2} / 4 \widetilde{\mathrm{H}}_{1}$ : simetria alélica; $\widetilde{\mathrm{K}}_{\mathrm{D}} / \widetilde{\mathrm{K}}_{\mathrm{R}}$ : relação entre genes dominantes e recessivos; $\widetilde{\mathrm{h}}^{2} / \widetilde{\mathrm{H}}_{2}$ : número de genes com dominância; $\widetilde{\mathrm{h}}_{\mathrm{R}}^{2}$ : herdabilidade no sentido restrito; $\widetilde{\mathrm{h}}_{\mathrm{A}}^{2}$ : herdabilidade no sentido amplo.

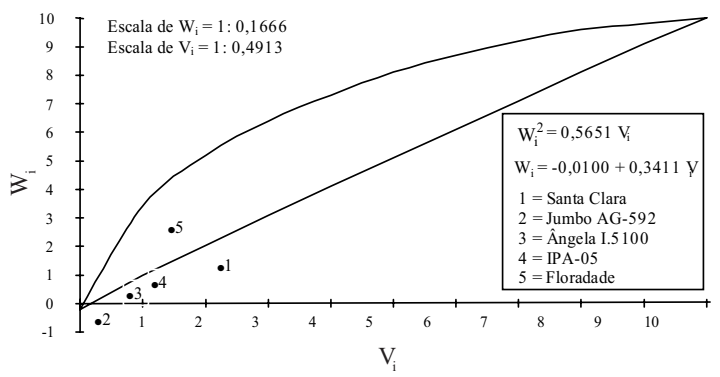

FIG. 4. Regressão de $W_{i}$ sobre $V_{i}$ em relação ao teor de sólidos solúveis. 
de melhoramento mais sofisticados são necessários para a obtenção de ganhos satisfatórios em gerações futuras.

\section{Teor de carotenóides totais dos frutos}

A baixa correlação negativa entre $\bar{y}_{i i}$ e $\left(\hat{W}_{\mathrm{i}}+\hat{\mathrm{V}}_{\mathrm{i}}\right)$, da ordem de $-0,1346$ (Tabela 2$)$, indica que apenas parte dos alelos dominantes é condicionante do aumento da característica.

A regressão de $\mathrm{W}_{\mathrm{i}}$ em função de $\mathrm{V}_{\mathrm{i}}$ mostra que $\hat{b}=0,1442$ não diferiu de 1,0 , a $1 \%$ de probabilidade; isto comprova que o modelo aditivo-dominante é adequado, não havendo evidência de epistasia. Contudo, numa análise crítica, é necessário ressaltar que um valor de $\hat{b}$ com esta magnitude não retrata uma real igualdade à unidade, motivo pelo qual a Fig. 5 deve ser analisada com cautela. Nessa figura, apresentam-se todos os genitores próximos ao limite de dominância que permitiria a máxima expressão do teor de carotenóides nos frutos. Se parte dos alelos dominantes é responsável pelo aumento da característica, isso evidencia uma situação favorável ao melhoramento. Todavia, esta não é a real situação que ocorre, uma vez que os genitores não se mostraram excelentes quanto ao nível de carotenóides nos frutos, como ocorre com o genitor 4, de maior concentração de alelos dominantes, que obteve média de 1,27 $\mu \mathrm{g} / 100 \mathrm{~g}$ de fruto, a qual é bastante aquém da média preconizada por Grierson \& Kader (1986), ou seja, $600 \mu \mathrm{g} / 100 \mathrm{~g}$ de fruto. Por conseguinte, presume-se que o reduzido nível, bem como a pequena variação quanto ao teor de carotenóides nos frutos, entre os genitores, é a principal razão da mencionada aglomeração dos

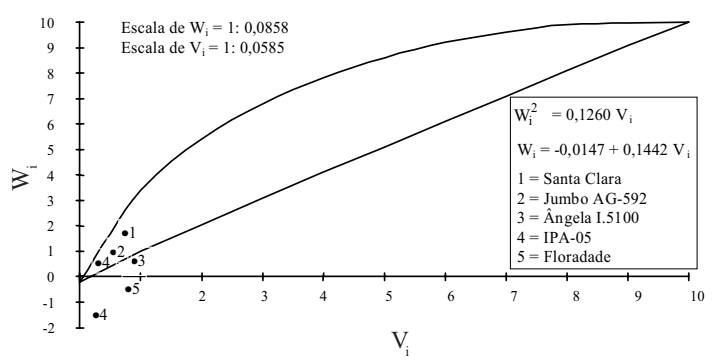

FIG. 5. Regressão de $W_{i}$ sobre $V_{i}$ em relação ao teor de carotenóides totais. genótipos. Dessa feita, duas considerações merecem atenção: a) a aplicação de quaisquer métodos de melhoramento seria beneficiada se novos genótipos com teores de carotenóides mais elevados fossem introduzidos nas populações; e b) de maneira geral, os melhoristas têm negligenciado as características de qualidade dos frutos em seus programas de melhoramento com tomateiro.

Pela Tabela 10, percebe-se a ocorrência de assimetria alélica entre os genitores, com base nos valores de 0,1764 para $\widetilde{\mathrm{H}}_{2} / 4 \widetilde{\mathrm{H}}_{1}$ e 1,5454 para $\widetilde{\mathrm{K}}_{\mathrm{D}} / \widetilde{\mathrm{K}}_{\mathrm{R}}$, mostrando que os genes dominantes e recessivos não se encontram eqüidistantemente distribuídos entre os genitores, o que reforça o fato de os genótipos se encontrarem inadequadamente posicionados no eixo da regressão de $\mathrm{W}_{\mathrm{i}}$ sobre $\mathrm{V}_{\mathrm{i}}$.

Os efeitos de dominância foram predominantes, em virtude do valor $-0,3729$ para $\widetilde{\mathrm{D}}-\widetilde{\mathrm{H}}_{1}$ (Tabela 10), havendo prevalência da sobredominância, de acordo com a estatística $\sqrt{\widetilde{\mathrm{H}}_{1} / \widetilde{\mathrm{D}}}$, por revelar a magnitude de 2,0583 .

TABELA 10. Estimativas dos componentes e das informações genéticas referentes à característica conteúdo de corotenóides totais dos frutos com relação a cinco genitores de tomateiro, segundo a metodologia de Hayman (1954).

\begin{tabular}{|c|c|c|c|}
\hline Componentes $^{1}$ & Estimativas & Informações $^{2}$ & Estimativas \\
\hline$\widetilde{\varepsilon}$ & 0,0108 & $\sqrt{\widetilde{\mathrm{H}}_{1} / \widetilde{\mathrm{D}}}$ & 2,0583 \\
\hline$\widetilde{\mathrm{D}}$ & 0,1151 & $\widetilde{\mathrm{H}}_{2} / 4 \widetilde{\mathrm{H}}_{1}$ & 0,1764 \\
\hline$\widetilde{\mathrm{H}}_{1}$ & 0,4880 & $\widetilde{\mathrm{K}}_{\mathrm{D}} / \widetilde{\mathrm{K}}_{\mathrm{R}}$ & 1,5454 \\
\hline$\widetilde{\mathrm{H}}_{2}$ & 0,3444 & $\widetilde{\mathrm{h}}^{2} / \widetilde{\mathrm{H}}_{2}$ & 0,3523 \\
\hline$\tilde{\mathrm{h}}^{2}$ & 0,1213 & $\widetilde{\mathrm{h}}_{\mathrm{R}}^{2}$ & 0,4476 \\
\hline$\widetilde{F}$ & 0,1016 & $\tilde{\mathrm{h}}_{\mathrm{A}}^{2}$ & 0,9382 \\
\hline$\widetilde{\mathrm{D}}-\widetilde{\mathrm{H}}_{1}$ & $-0,3729$ & & \\
\hline \multicolumn{4}{|c|}{$\begin{array}{l}1 \widetilde{\varepsilon}: \text { componente associado ao erro experimental; } \widetilde{\mathrm{D}}: \text { componente } \\
\text { associado aos efeitos aditivos; } \widetilde{\mathrm{H}}_{1}, \widetilde{\mathrm{H}}_{2} \text { e } \widetilde{\mathrm{h}}^{2}: \text { componentes associados } \\
\text { aos efeitos de dominância; } \widetilde{\mathrm{F}}: \text { covariância entre os efeitos aditivos e } \\
\text { dominantes; } \widetilde{\mathrm{D}} \text { - } \widetilde{\mathrm{H}}_{1}: \text { componente que expressa a diferença entre os efei- } \\
\text { tos aditivos e dominantes. } \\
2 \sqrt{\widetilde{\mathrm{H}}_{1} / \widetilde{\mathrm{D}}} \text { : grau médio de dominância; } \widetilde{\mathrm{H}}_{2} / 4 \widetilde{\mathrm{H}}_{1}: \text { simetria alélica; } \\
\widetilde{\mathrm{K}}_{\mathrm{D}} / \widetilde{\mathrm{K}}_{\mathrm{R}} \text { : relação entre genes dominantes e recessivos; } \widetilde{\mathrm{h}}^{2} / \widetilde{\mathrm{H}}_{2}: \text { nú- } \\
\text { mero de genes com dominância; } \widetilde{\mathrm{h}}_{\mathrm{R}}^{2}: \text { herdabilidade no sentido restrito; } \\
\widetilde{\mathrm{h}}_{\mathrm{A}}^{2} \text { : herdabilidade no sentido amplo. }\end{array}$} \\
\hline
\end{tabular}




\section{Porcentagem de licopeno dos frutos}

$\mathrm{Na}$ Tabela 2, constata-se que os alelos dominantes, em sua maioria, são responsáveis pelo aumento do percentual de licopeno nos frutos, evidenciado pelo valor $-0,7308$ referente à correlação entre $\bar{y}_{\text {ii }}$ $\mathrm{e}\left(\hat{\mathrm{W}}_{\mathrm{i}}+\hat{\mathrm{V}}_{\mathrm{i}}\right)$. Os genitores com maior concentração de alelos dominantes são, em ordem decrescente: $3,1,2$, 4 e 5, como se pode ver na Fig. 6. Assim, o genitor 3 seria indicado para programas intrapopulacionais, visando à obtenção de descendentes com maiores percentuais de licopeno nos frutos. Contudo, tendo em vista que os componentes aditivos foram bastante inferiores aos de dominância ( $\left.\widetilde{\mathrm{D}}-\widetilde{\mathrm{H}}_{1}=-5,6001\right)$, de acordo com o mostrado na Tabela 11, a estratégia interpopulacional de melhoramento parece ser a alternativa mais viável quando se objetivam incrementos nos percentuais de licopeno em gerações futuras.

A elevada superioridade dos componentes de dominância explica a sobredominância constatada na característica, via $\sqrt{\widetilde{\mathrm{H}}_{1} / \widetilde{\mathrm{D}}}$ (Tabela 11), o que é retratado na Fig. 6, na qual a linha de regressão corta o eixo $\mathrm{w}_{\mathrm{i}}$ abaixo da origem. A distribuição dos alelos entre os genitores ocorre de maneira simétrica, considerando-se os valores 0,2370 para $\widetilde{\mathrm{H}}_{2} / 4 \widetilde{\mathrm{H}}_{1}$ e 1,0606 para $\widetilde{\mathrm{K}}_{\mathrm{D}} / \widetilde{\mathrm{K}}_{\mathrm{R}}$ (Tabela 11 ).

\section{Teor de betacaroteno dos frutos}

Considerando o valor 0,1464 para a correlação entre $\bar{y}_{i i}$ e $\left(\hat{W}_{i}+\hat{V}_{i}\right)$, como mostrado na Tabela 2, pode-se inferir que parte dos alelos recessivos concorre para provocar aumentos no teor de betacaroteno dos frutos.

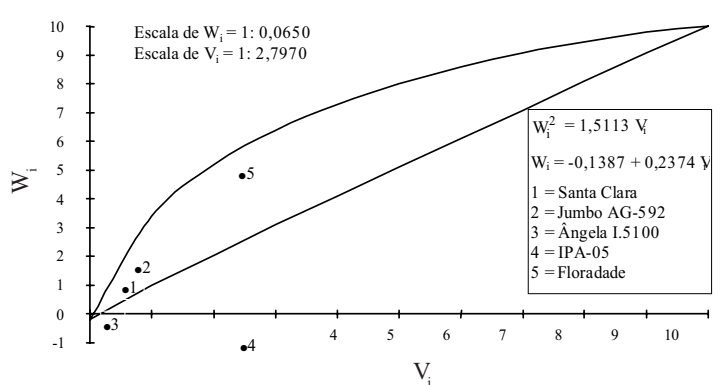

FIG. 6. Regressão de $\mathrm{W}_{\mathrm{i}}$ sobre $\mathrm{V}_{\mathrm{i}}$ em relação à porcentagem de licopeno.
De forma análoga ao teor de carotenóides totais, para teor de betacaroteno, houve concentração dos genitores no extremo dominante do gráfico de regressão de $\mathrm{W}_{\mathrm{i}}$ sobre $\mathrm{V}_{\mathrm{i}}$ (Fig. 7). Ao que parece, os baixos teores de betacaroteno nos frutos, aliados à reduzida variação em suas médias foram os princi-

TABELA 11. Estimativas dos componentes e das informações genéticas referentes à característica porcentagem de licopeno dos frutos com relação a cinco genitores de tomateiro, segundo a metodologia de Hayman (1954).

\begin{tabular}{cccc}
\hline Componentes $^{1}$ & Estimativas $^{\text {Informações }^{2}}$ & Estimativas \\
\hline$\widetilde{\varepsilon}$ & 0,8596 & $\sqrt{\widetilde{\mathrm{H}}_{1} / \widetilde{\mathrm{D}}}$ & 3,0973 \\
$\widetilde{\mathrm{D}}$ & 0,6516 & $\widetilde{\mathrm{H}}_{2} / 4 \widetilde{\mathrm{H}}_{1}$ & 0,2370 \\
$\widetilde{\mathrm{H}}_{1}$ & 6,2518 & $\widetilde{\mathrm{K}}_{\mathrm{D}} / \widetilde{\mathrm{K}}_{\mathrm{R}}$ & 1,0606 \\
$\widetilde{\mathrm{H}}_{2}$ & 5,9282 & $\widetilde{\mathrm{h}}^{2} / \widetilde{\mathrm{H}}_{2}$ & 0,0733 \\
$\widetilde{\mathrm{h}}^{2}$ & 0,4347 & $\widetilde{\mathrm{h}}_{\mathrm{R}}^{2}$ & 0,1546 \\
$\widetilde{\mathrm{F}}$ & 0,1188 & $\widetilde{\mathrm{h}}_{\mathrm{A}}^{2}$ & 0,6896 \\
$\widetilde{\mathrm{D}}-\widetilde{\mathrm{H}}_{1}$ & $-5,6001$ & & \\
\hline
\end{tabular}

$\widetilde{\varepsilon}$ : componente associado ao erro experimental; $\widetilde{\mathrm{D}}:$ componente associado aos efeitos aditivos; $\widetilde{\mathrm{H}}_{1}, \widetilde{\mathrm{H}}_{2} \mathrm{e} \widetilde{\mathrm{h}}^{2}$ : componentes associados aos efeitos de dominância; $\widetilde{\mathrm{F}}$ : covariância entre os efeitos aditivos e dominantes; $\widetilde{\mathrm{D}}-\widetilde{\mathrm{H}}_{1}$ : componente que expressa a diferença entre os efeitos aditivos e dominantes.

$2 \sqrt{\widetilde{\mathrm{H}}_{1} / \widetilde{\mathrm{D}}}$ : grau médio de dominância; $\widetilde{\mathrm{H}}_{2} / 4 \widetilde{\mathrm{H}}_{1}$ : simetria alélica; $\widetilde{\mathrm{K}}_{\mathrm{D}} / \widetilde{\mathrm{K}}_{\mathrm{R}}$ : relação entre genes dominantes e recessivos; $\widetilde{\mathrm{h}}^{2} / \widetilde{\mathrm{H}}_{2}$ : número de genes com dominância; $\widetilde{\mathrm{h}}_{\mathrm{R}}^{2}$ : herdabilidade no sentido restrito; $\widetilde{\mathrm{h}}_{\mathrm{A}}^{2}$ : herdabilidade no sentido amplo.

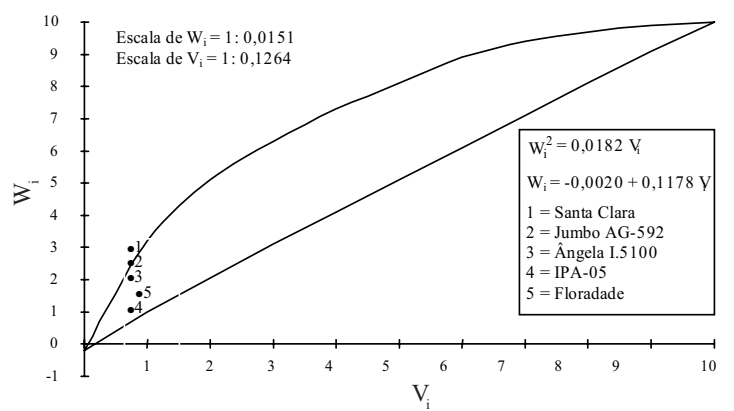

FIG. 7. Regressão de $W_{i}$ sobre $V_{i}$ em relação ao teor de betacaroteno.

Pesq. agropec. bras., Brasília, v.34, n.8, p.1407-1416, ago. 1999 
pais fatores que provocaram a presente situação, de forma semelhante ao aventado com relação ao teor de carotenóides totais. Tal fato é retratado pela assimetria na distribuição alélica, em razão dos valores expressos pelas estatísticas $\widetilde{\mathrm{H}}_{2} / 4 \widetilde{\mathrm{H}}_{1}$ e $\widetilde{\mathrm{K}}_{\mathrm{D}} / \widetilde{\mathrm{K}}_{\mathrm{R}}$, respectivamente 0,1832 e 1,5602 (Tabela 12). Logo, a introdução de novos genótipos na população, com teores mais elevados de betacaroteno, seria uma estratégia mais eficiente na busca de híbridos e segregantes superiores.

A exemplo do teor de carotenóides totais, houve preponderância dos efeitos de dominância, em virtude do valor $-0,0481$ para $\widetilde{\mathrm{D}}-\widetilde{\mathrm{H}}_{1}$, ocorrendo também a sobredominância, como interação alélica, com base na magnitude 1,9730 para a estatística $\sqrt{\widetilde{\mathrm{H}}_{1} / \widetilde{\mathrm{D}}}$ (Tabela 12), além de a reta de regressão de $\mathrm{W}_{\mathrm{i}}$ sobre $\mathrm{V}_{\mathrm{i}}$ tocar o eixo $\mathrm{W}_{\mathrm{i}}$ abaixo da origem.

TABELA 12. Estimativas dos componentes e das informações genéticas referentes à característica teor de betacaroteno dos frutos com relação a cinco genitores de tomateiro, segundo a metodologia de Hayman (1954).

\begin{tabular}{cccc}
\hline Componentes $^{1}$ & Estimativas & Informaçoes $^{2}$ & Estimativas \\
\hline$\widetilde{\varepsilon}$ & 0,0016 & $\sqrt{\widetilde{\mathrm{H}}_{1} / \widetilde{\mathrm{D}}}$ & 1,9730 \\
$\widetilde{\mathrm{D}}$ & 0,0166 & $\widetilde{\mathrm{H}}_{2} / 4 \widetilde{\mathrm{H}}_{1}$ & 0,1832 \\
$\widetilde{\mathrm{H}}_{1}$ & 0,0647 & $\widetilde{\mathrm{K}}_{\mathrm{D}} / \widetilde{\mathrm{K}}_{\mathrm{R}}$ & 1,5602 \\
$\widetilde{\mathrm{H}}_{2}$ & 0,0474 & $\widetilde{\mathrm{h}}^{2} / \widetilde{\mathrm{H}}_{2}$ & 0,3905 \\
$\widetilde{\mathrm{h}}^{2}$ & 0,0185 & $\widetilde{\mathrm{h}}_{\mathrm{R}}^{2}$ & 0,4203 \\
$\widetilde{\mathrm{F}}$ & 0,0143 & $\widetilde{\mathrm{h}}_{\mathrm{A}}^{2}$ & 0,9302 \\
$\widetilde{\mathrm{D}}-\widetilde{\mathrm{H}}_{1}$ & $-0,0481$ & & \\
\hline
\end{tabular}

$1 \widetilde{\varepsilon}$ : componente associado ao erro experimental; $\widetilde{\mathrm{D}}$ : componente associado aos efeitos aditivos; $\widetilde{\mathrm{H}}_{1}, \widetilde{\mathrm{H}}_{2} \mathrm{e} \widetilde{\mathrm{h}}^{2}$ : componentes associados aos efeitos de dominância; $\widetilde{\mathrm{F}}$ : covariância entre os efeitos aditivos e dominantes; $\widetilde{\mathrm{D}}-\widetilde{\mathrm{H}}_{1}$ : componente que expressa a diferença entre os efeitos aditivos e dominantes.

$2 \sqrt{\widetilde{\mathrm{H}}_{1} / \widetilde{\mathrm{D}}}$ : grau médio de dominância; $\widetilde{\mathrm{H}}_{2} / 4 \widetilde{\mathrm{H}}_{1}$ : simetria alélica; $\widetilde{\mathrm{K}}_{\mathrm{D}} / \widetilde{\mathrm{K}}_{\mathrm{R}}$ : relação entre genes dominantes e recessivos; $\widetilde{\mathrm{h}}^{2} / \widetilde{\mathrm{H}}_{2}$ : número de genes com dominância; $\widetilde{\mathrm{h}}_{\mathrm{R}}^{2}$ : herdabilidade no sentido restrito; $\widetilde{\mathrm{h}}_{\mathrm{A}}^{2}$ : herdabilidade no sentido amplo.

\section{CONCLUSÕES}

1. Pela metodologia de Hayman (1954), há possibilidade de ganhos genéticos, via programas de melhoramento intrapopulacionais, referentes às características relacionadas à produção, o mesmo não ocorrendo com os teores de sólidos solúveis, de carotenóides totais e de betacaroteno.

2. Os baixos níveis de teor de carotenóides totais, bem como de betacaroteno nas cultivares avaliadas, atestam que as características da qualidade dos frutos têm sido negligenciadas em programas de melhoramento.

\section{REFERÊNCIAS}

CARVALHO, L.P. Divergência genética e análise dialélica em Gossypium hirsutum L. var. latifolium Hutch. Viçosa: UFV, Impr. Univ., 1993. 203p. Tese de Mestrado.

CRUZ, C.D. Programa Genes: aplicativo computacional em genética e estatística. Viçosa, MG: UFV, 1997. $442 \mathrm{p}$.

CRUZ, C.D.; REGAZZI, A.J. Modelos biométricos aplicados ao melhoramento genético. Viçosa: UFV, Impr. Univ., 1994. 394p.

GRIERSON, D.; KADER, A.A. Fruit ripening and quality. In: ATHERTON, J.G.; RUDICH, J. The tomato crop: a scientific basis for improvement. London: Chapman and Hall, 1986. p.241-280.

HAYMAN, B.I. The theory and analysis of diallel crosses. Genetics, v.39, p.789-809, 1954.

HOAGLAND, D.R.; ARNON, D.I. The water-culture method for growing plants without soil. Okland: California Agricultural Experiment Station, 1950. 23p. (Bulletin, 347).

MALUF, W.R.; MIRANDA, J.E.C. de; CAMPOS, J.P. de. Análise genética de um cruzamento dialélico de cultivares de tomate. I. Características referentes à produção de frutos. Pesquisa Agropecuária Brasileira, Brasília, v.17, n.4, p.633-641, abr. 1982.

ZSCHEILE, F.P.; PORTER, J.W. Analytical methods for carotenes of Lycopersicon species and strains. Analytical Chemistry, v.19, n.47-51, 1947. 